Article

\title{
Endocytosis Pathways of the Folate Tethered Star-Shaped PEG-PCL Micelles in Cancer Cell Lines
}

\author{
Yu-Lun Li ${ }^{1}$, Nguyen Van Cuong ${ }^{1,4}$ and Ming-Fa Hsieh ${ }^{1,2,3, *}$
}

1 Department of Biomedical Engineering, Chung Yuan Christian University, No. 200, Chung-Pei Rd., Chung Li 32023, Taiwan; E-Mails: lun1126123@hotmail.com (Y.-L.L.); nvc@hui.edu.vn (N.V.C.)

2 Center for Nanotechnology, Chung Yuan Christian University, 200, Chung-Pei Rd., Chung Li 32023, Taiwan

3 Center of Biomedical Technology, Chung Yuan Christian University, 200, Chung-Pei Rd., Chung Li 32023, Taiwan

4 Department of Chemical Engineering, Industrial University of Ho Chi Minh City, 12 Nguyen Van Bao Road, GoVap Dist., Ho Cho Minh City 7000, Vietnam

* Author to whom correspondence should be addressed; E-Mail: mfhsieh@cycu.edu.tw; Tel.: +886-3-265-4550; Fax: +886-3-265-4599.

Received: 17 December 2013; in revised form: 20 February 2014 / Accepted: 24 February 2014 / Published: 6 March 2014

\begin{abstract}
This study reports on the cellular uptake of folate tethered micelles using a branched skeleton of poly(ethylene glycol) and poly( $\varepsilon$-caprolactone). The chemical structures of the copolymers were characterized by proton nuclear magnetic resonance spectroscopy, and Fourier transform infrared spectroscopy. Doxorubicin (DOX) was utilized as an anticancer drug. The highest drug loading efficiencies of DOX in the folate decorated micelle (DMCF) and folate-free micelle (DMC) were found to be $88.5 \%$ and $88.2 \%$, respectively, depending on the segment length of the poly( $\varepsilon$-caprolactone) in the copolymers. A comparison of fluorescent microscopic images of the endocytosis pathway in two cell lines, human breast cancer cells (MCF-7) and human oral cavity carcinoma cells (KB), revealed that the micelles were engulfed by $\mathrm{KB}$ and MCF-7 cells following in vitro incubation for one hour. Flow cytometric analysis revealed that free folic acid can inhibit the uptake of DOX by $48 \%-57 \%$ and $26 \%-39 \%$ in KB cells and MCF-7 cells, respectively. These results prove that $\mathrm{KB}$ cells are relatively sensitive to folate-tethered micelles. Upon administering methyl- $\beta$-cyclodextrin, an inhibitor of the caveolae-mediated endocytosis pathway, the uptake of DOX by KB cells was reduced by $69 \%$ and that by MCF-7 cells was reduced by $56 \%$. This finding suggests that DMCF enters cells via multiple pathways,
\end{abstract}


thus implying that the folate receptor is not the only target of tumor therapeutics.

Keywords: copolymer; drug delivery targeting; endocytosis pathway; folate receptor

\section{Introduction}

Conventional nanocarriers are associated with systemic toxicity and poor bioavailability of anti-tumor drugs because they have undesired specificity. The active targeting of tumor therapeutics has been shown to improve drug accumulation at tumor sites [1,2]. The plasma surface of cancer cells is expressed with various receptors depending on the physiological functions of the cells. Folate receptor (FR) is a membrane-bound protein with high affinity for binding and transporting physiological levels of folate into cells. FR is over-expressed in the apical membrane surface of certain cancer cells including ovary, kidney, uterus, colon, and lung, making a potential target for tumor therapeutics [2-4]. Cellular uptake of folate is increased by a reduced folate carrier and/or the proton-coupled folate transporter or the glycosylphosphatidylinositol-linked folate receptor [5]. To exploit these effects, folic acid was conjugated with macromolecules [6], liposomes [7] or nanoparticles [8,9] to target malignant cells with the drug molecules. For example, folic acid was conjugated with poly (D,L-lactic-co-glycolic acid)-poly(ethylene glycol), poly(L-histidine- $c o$-L-phenlyalanine- $b$-PEG and poly(L-lactic acid)- $b$ PEG-folate [10], and such conjugation was demonstrated to enhance doxorubicin and paclitaxel delivery to folate receptor-expressing cancer cells in vitro and in vivo. Particularly interesting, the tumor distribution of irinotecan-loaded FR-targeted liposomes was greater than that of unmodified liposome which might contribute to folate-mediated targeting uptake by the folate receptor on the surface of the tumor cells [11]. The nanoparticles are internalized into cells via several endocytic pathways: such as phagocytosis, pinocytosis, and caveolae-dependent or clathrin-mediated endocytosis [12-14]. FR is known to be able to transport folic-decorated nanoparticles into cells via receptor-mediated endocytosis. Moreover, caveolae-dependent endocytosis was reported to be involved in the uptake of FA in some cases [15,16]. The complete mechanism is complex and under debate [12]. More detailed knowledge of the cellular uptake and cell internalization mechanism is required because each pathway has its own characteristics, which should be taken into account in the optimization of drug delivery systems. Understanding the detailed mechanism of cellular uptake is an important step towards understanding the biological fate of nanoparticles, both adverse and favorable aspects.

The authors recently described the preparation of triblock, star-shaped micelles and folate-decorated micelles and their cytotoxic effects on human breast cancer cell lines (MCF-7) [17-19,20]. These formulations have been demonstrated to have potential applications in anti-cancer drug delivery because drug-micelles are internalized into cells via endocytosis pathways. In contrast, free drugs are internalized into cells by a diffusion mechanism, and so have a higher cytotoxicity against cancer cells. The two broad endocytic pathways are phagocytosis (uptake of large particles) and pinocytosis (uptake of endocytosis fluids and solutes by clathrin-dependent and non-clathrin-dependent pathways). The purpose of this work is to synthesize and characterize a new class of doxorubicin (DOX)-loaded micelles using folate-decorated star-shaped copolymer. The drug loading content of doxorubicin-loaded micelles, its drug loading efficiency and the release of DOX from the micelle were measured. 
Furthermore, the cellular uptake mechanism and potential endocytosis pathways of FA-decorated micelles in carcinoma cells (KB) cells and MCF-7 cells were further examined using specific inhibitors of the various endocytic pathways.

\section{Materials and Methods}

\subsection{Materials}

Pentaerythritol ethoxylate $(\mathrm{EO} / \mathrm{OH} 15 / 4)$, $\varepsilon$-caprolactone, doxorubicin hydrochloride $(\mathrm{DOX} \cdot \mathrm{HCl})$, 2-diphenyl-1,3,5-hexatriene (DPH), and dimethylsulfoxide (DMSO) were obtained from Sigma-Aldrich Chem. Co. Inc. (St. Louis, MO, USA). Stannous octoate ( $\left.\mathrm{Sn}(\mathrm{Oct})_{2}\right)$ was obtained from MP Biomedicals Inc., (Santa Ana, CA, USA). The polyethylene glycol (PEG) polymer with a terminal hydroxyl and carboxylic acid functional groups $\left(\mathrm{OH}-\mathrm{PEG}_{3400}-\mathrm{COOH}\right)$ was custom synthesized by Biomatrik (Zhejiang, China). 4-Dimethylaminopyridine (DMAP) and $N, N^{\prime}$-dicyclohexylcarbodiimide (DCC) were purchased from Alfa Aesar, A Johnson Matthey Company, (Ward Hill, MA, USA). Tetrahydrofuran (THF) was distilled from metallic sodium and benzophenone. Triethylamine (TEA), dichloromethane (DCM), hexane and diethyl ether were purchased from Echo Chemicals (Miaoli, Taiwan) and used as received. Cystamine dihydrochloride (Cystamine·2HCl, >98\%), p-nitrophenyl chloroformate (NPC) and $N$-hydroxysuccinimide (NHS) were obtained from Acros Organics (Geel, Belgium).

A human breast cancer cell line: drug-sensitive cell (MCF-7) and a human oral carcinoma cell line (KB) were kindly donated by Dr. Chen of School of Pharmacy, College of Medicine National Taiwan University, Taipei, Taiwan for use in the cell culture experiments. 3-(4,5-Dimethylthiazol-2-yl)-2,5diphenyl tetrazolium bromide (MTT) was obtained from Sigma-Aldrich Chem. Co. Inc (St. Louis, MO, USA). Dulbecco's Modified Eagle's Medium (DMEM) and antibiotic antimycotic were purchased from Invitrogen Corporation (Grand Island, NY, USA). Fetal bovine serum (FBS) was obtained from HyClone Thermo Fisher Scientific Inc (Waltham, MA, USA). Methyl- $\beta$-cyclodextrin, chlorpromazine and cytochalasin D were obtained from Sigma-Aldrich Chem. Co. Inc.

\subsection{Synthesis of Folic-Tethered Star-Shaped Poly(E-Caprolactone)-Poly(Ethylene Glycol) Block Copolymer 4SPCL-PEG-Folic}

4SPCL-PEG and 4SPCL-PEG-Folic were prepared elsewhere [17]. Each preparation consisted of four steps, where the synthesis of star-shaped poly( $\varepsilon$-caprolactone) polymers (PCL) begins by an open ring polymerization reaction, activation of 4SPCL with NPC, conversion of a terminal carboxylic acid group of $\mathrm{OH}-\mathrm{PEG}_{3400}-\mathrm{COOH}$ into an amino functional group $\left(\mathrm{NH}_{2}-\mathrm{PEG}-\mathrm{OH}\right)$, coupling of activated 4SPCL with $\mathrm{NH}_{2}-\mathrm{PEG}-\mathrm{OH}$ and conjugation with folic acid via carbodiimide chemistry. Figure 1 displays the reaction schemes for preparing 4SPCL-PEG and 4SPCL-PEG-Folic copolymers. Briefly, in a nitrogen atmosphere, a DCM solution $(5 \mathrm{~mL})$ of $\mathrm{OH}-\mathrm{PEG}-\mathrm{NH}_{2}(240 \mathrm{mg}, 0.07 \mathrm{mmol})$, star-shaped polymer PCL-NPC (105 mg, $0.017 \mathrm{mmol})$, and $10 \mathrm{uL}$ TEA were stirred at room temperature for $48 \mathrm{~h}$. Folic acid $(0.05 \mathrm{mmol}, 22 \mathrm{mg})$ and DCC $(0.06 \mathrm{mmol}, 12.4 \mathrm{mg})$ were dissolved in DMSO ( $3 \mathrm{~mL})$. The mixture was stirred at room temperature for $24 \mathrm{~h}$. The folic acid in DMSO was mixed with the above solution with the addition of DMAP $(0.006 \mathrm{mmol}, 1.0 \mathrm{mg})$ and stirred for $24 \mathrm{~h}$. The precipitated 
product was removed using a centrifuge. The supernatant was dialyzed against DMSO for $24 \mathrm{~h}$ and DD water for $24 \mathrm{~h}$, before being lyophilized.

\subsection{Preparation and Characteristic of 4SPCL-PEG-Folic Micelles}

To prepare the DOX-unloaded micelles, a micellar solution was prepared by dissolving $5 \mathrm{mg}$ of copolymer in $1.0 \mathrm{~mL}$ of a mixture of THF and DMSO $(1: 1, \mathrm{v} / \mathrm{v})$ and then $1.0 \mathrm{~mL}$ of deionized water (18.2 $\mathrm{m} \Omega \cdot \mathrm{cm}$ resistivity) was added with stirring. The resulting solution was placed at room temperature for $3 \mathrm{~h}$ and then was transferred to a dialysis bag before being dialyzed against $1 \mathrm{~L}$ of deionized water for 24 h (MWCO: 8000 Da, Spectrum Laboratories, Rancho Dominguez, CA, USA). The water was replaced hourly for the first $3 \mathrm{~h}$. The micellar solution was diluted to $0.5 \mathrm{mg} / \mathrm{mL}$ for the sizes of the particles to be measured.

To prepare the DOX-loaded micelles, $2.0 \mathrm{mg}$ of DOX was neutralized with an excess amount of TEA in $1.0 \mathrm{~mL}$ of THF/DMSO $(1: 1, \mathrm{v} / \mathrm{v})$. The DOX solution was then added to the $1.0 \mathrm{~mL}$ THF/DMSO (1:1, v/v) solution, which contained $20 \mathrm{mg}$ copolymer. This solution was added to $1.0 \mathrm{~mL}$ deionized water with stirring for $3 \mathrm{~h}$. The mixture was transferred for dialysis against $1 \mathrm{~L}$ of deionized water for $24 \mathrm{~h}$ to produce the DOX-loaded micelles. The water was replaced hourly for the first $3 \mathrm{~h}$, and then refreshed once every three hours until no red color of DOX was observed in the dialysate. The drug loading efficiency (DLE) is defined as the weight of DOX in the micelles as a percentage of the initial feed amount weight of DOX. The drug loading content (DLC) is estimated from the mass of incorporated DOX into the micelles divided by the mass of the copolymer. The amount of DOX-loaded in the micelles was determined using a JASCO UV-530 UV-Vis spectrometer (JASCO, Inc., Easton, MD, USA) at $485 \mathrm{~nm}$ [21].

Particle size and zeta potential measurements: The distribution of particle sizes was determined by dynamic light scattering (DLS) using a Zetasizer 3000HSA instrument (Malvern, UK) at a fixed angle of $90^{\circ}$ and a laser wavelength of $633.0 \mathrm{~nm}$ at $25{ }^{\circ} \mathrm{C}$. The mean diameter calculated from ten measurements. The zeta potential was measured using an aqueous dip cell in automatic mode using a Zetasizer 3000HSA instrument from Malvern (Malvern, UK).

\subsection{Experiment on in Vitro Release of DOX from 4SPCL-PEG-Folic Micelles}

An experiment was carried out following a procedure that was described elsewhere [17]. Briefly, $1.0 \mathrm{~mL}$ of DOX-loaded micellar solution was dissolved in $1.0 \mathrm{~mL}$ phosphate buffer solution (PBS) (0.1 M, pH 7.4) and acetate buffer solution (0.1 M, pH 5.4), and each was separately transferred into a dialysis tube (MWCO: $8000 \mathrm{Da}$ ). The tube was immersed into $50 \mathrm{~mL}$ of phosphate or acetate buffer solution, which was maintained at $37^{\circ} \mathrm{C}$. At various times, $1.0 \mathrm{~mL}$ of the buffer solution outside the dialysis bag was withdrawn for UV-Vis analysis and replaced with $1 \mathrm{~mL}$ of fresh buffer solution. The DOX concentration was calculated from the absorbance at $485 \mathrm{~nm}$.

\subsection{In Vitro Cytotoxicity of DOX-Loaded Micelle in KB and MCF-7 Cell Lines}

KB and MCF-7 cells were seeded in 96-well plates at a density of $2 \times 10^{3}$ cells/well and were incubated at $37{ }^{\circ} \mathrm{C}$ in a humidified atmosphere that contained $5 \% \mathrm{CO}_{2}$ for $24 \mathrm{~h}$ before assay. Thereafter, the cells 
were further incubated in a cell medium with 10\% fetal bovine serum (Gibco, Grand Island, NY, USA) that contained free $\mathrm{DOX}, \mathrm{DMC}_{100}$ or $\mathrm{DMC}_{100} \mathrm{~F}$ of various DOX concentrations $(0.01-20 \mu \mathrm{g} / \mathrm{mL})$ for $48 \mathrm{~h}$. A solution of medium with unloaded micelles (placebo) was used as a control to yield results that could be compared with those obtained from the DOX-loaded micelle. The same experiment was conducted using media that contained $100 \mu \mathrm{g} / \mathrm{mL}$ free folic acid to determine the effect of the FR blockade. At various times, 3-(4,5-dimethylthiazol-2-yl)-2,5-diphenyltetrazolium bromide (MTT) solution was added to each well, and the contents were incubated at $37{ }^{\circ} \mathrm{C}$ for $4 \mathrm{~h}$. Thereafter, the medium was removed and violet crystals were solubilized with DMSO. The absorbance of each well was determined using a Multiskan Spectrum spectrophotometer (Thermo Electron Corporation, Waltham, MA, USA) at $570 \mathrm{~nm}$ and $630 \mathrm{~nm}$. The cell viability (\%) was calculated as the ratio of the number of surviving cells in drug-treated samples to that in the control.

\subsection{Cellular Uptake of DOX-Loaded Micelles in the MCF-7 and KB Cell Lines}

\subsubsection{Flow Cytometry}

The intracellular uptake of doxorubicin was evaluated by flow cytometry, using a FACSCalibur flow cytometer (BD Biosciences, San Jose, CA, USA). Then $2 \times 10^{5}$ cells (KB and MCF-7 cell lines) were incubated in the culture medium for two days and afterwards separately treated with free DOX, $\mathrm{DMC}_{100}$ and $\mathrm{DMC}_{100} \mathrm{~F}$, in a medium that contained $\mathrm{DOX}$ at a concentration at $5 \mu \mathrm{g} / \mathrm{mL}$ and $10 \mu \mathrm{g} / \mathrm{mL}$ DOX equivalents for $2 \mathrm{~h}$. The medium was removed after $2 \mathrm{~h}$ and washed twice with PBS, and then trypsin was added and left to stand for $2 \mathrm{~min}$. The cells were harvested and centrifuged at $1500 \mathrm{rpm}$. Cells in $12 \times 75$ Falcon tubes were placed on the FACSCalibur. The fluorescence intensity of DOX was measured at $488 \mathrm{~nm}$ excitation using a $575 \mathrm{~nm}$ band pass filter.

\subsubsection{Cellular Uptake of DOX}

To evaluate the intracellular uptake of the drug into the cells, the uptakes of DOX-loaded micelles and free DOX by KB and MCF-7 cell lines were tested. The cells were seeded on coverslip glass $\left(3 \times 10^{5}\right.$ cells/dish $)$ and incubated for two days. The cells were then incubated with $\mathrm{DMC}_{100}$ and $\mathrm{DMC}_{100} \mathrm{~F}$ in a medium that contained DOX at a concentration of $5 \mu \mathrm{g} / \mathrm{mL}$. After $3 \mathrm{~h}$, the medium was removed and the cells were washed twice using cold PBS. Fluorescence images of the cells were obtained using a confocal laser scanning microscope (A1R-A1, Nikon Instruments Inc., Melville, NY, USA).

\subsubsection{Pathways of Endocytosis}

KB and MCF-7 cell lines were seeded in a six-well plate with a density of $2 \times 10^{5}$ cells/well and incubated for two days. The cells had been pre-incubated with inhibitors (methyl- $\beta$-cyclodextrin, chlorpromazine and cytochalasin D) for $1 \mathrm{~h}$. The inhibitor solutions were removed and fresh DOX-loaded 4SPCL-PEG-FOL micelles in a medium that contained inhibitors were added and the system was incubated for $2 \mathrm{~h}$. The DOX concentration was $10 \mu \mathrm{g} / \mathrm{mL}$. The concentrations of chlorpromazine, methyl- $\beta$-cyclodextrin and cytochalasin $\mathrm{D}$ were $10 \mu \mathrm{g} / \mathrm{mL}, 10 \mathrm{mM}$ and $10 \mu \mathrm{g} / \mathrm{mL}$, respectively. The cells were collected and analyzed using a flow cytometer. The medium and DOX-micelles without inhibitors were used as controls. 


\section{Results and Discussion}

\subsection{Preparation and Micellization Behavior of 4SPCL-PEG-Folic Copolymer}

Figure 1 displays the synthesis of 4SPCL-PEG-Folic copolymer. The star-shaped block polymers PCL, with various molecular weights were activated with NPC. HO-PEG-COOH was activated with NHS and reacted with the cystamine to yield $\mathrm{OH}-\mathrm{PEG}-\mathrm{NH}_{2}$. Coupling of the activated PCL with $\mathrm{OH}-\mathrm{PEG}-\mathrm{NH}_{2}$ yielded star-shaped PCL-PEG-OH. These star-shaped copolymers were conjugated with folic acid using DMAP and DCC. As presented in Table 1, 4SPCL-PEG and folate-conjugated 4SPCL-PEG copolymers with various molecular weights of the PCL were synthesized. The structures of 4SPCL-PEG-Folic copolymers were obtained by ${ }^{1} \mathrm{H}$ NMR and FT-IR in our earlier study [17]. Doxorubicin, an anthracycline drug, is commonly administered for treating breast cancer as well as ovarian, prostate, brain, cervix and lung cancer. However, DOX was found to have cardiac toxicity, a short half life-time, and a low solubility in an aqueous solution [22]. To overcome the limitations, DOX micelles were prepared using copolymer with and without folic conjugation following evaporation of the solvent, resulting in the formation of DOX encapsulated in micelles. The diameters of DOX micelles with and without folic conjugation were in the range 97-209 nm, as verified using dynamic light scattering. As presented in Table 2, the particle size of the micelles increased with the molecular weight of the PCL segments. Note that the micelles are abbreviated as $\mathrm{DMC}_{x x x}$ or $\mathrm{DMC}_{x x x} \mathrm{~F}$ where $\mathrm{xxx}$ represent the segment length of PCL in this study. Additionally, the atomic force microscopy (AFM, JPK Instruments AG, Berlin, Germany) image showed a spherical shape of $\mathrm{DMC}_{100} \mathrm{~F}$ micelles having an average hydrodynamic diameter of approximately $100 \mathrm{~nm}$. As compared with the results of DLS measurements, the smaller size of the micelle is due to the AFM being measured in a dry state in comparison with the aqueous state of DLS [17]. Furthermore, the zeta potential of the micelles decreased following DOX loading and folic conjugation. The negative zeta potential of folic acid-tethered micelles has also been reported in a previous investigation [17,23]. The anti-cancer drug hydrophobic DOX was physically entrapped in the core of the micelles of the star-shaped copolymer. The drug loading efficiency of the DOX-incorporating micelles increased with the molecular weight of the poly( $\varepsilon$-caprolactone), because an increase in the hydrophobic chain length of the block copolymer improves the interaction between hydrophobic DOX and poly( $\varepsilon$-caprolactone) [24]. The conjugation of folic acid with 4SPCL-PEG did not significantly change the drug loading efficiency or drug loading content. The drug loading efficiency and drug loading content of 4SPCL-PEG-Folic micelle and 4SPCL-PEG micelle were $88.5 \%$ and $88.2 \%$, respectively. The in vitro release profiles of DOX from 4SPCL-PEG-Folic micelle and 4SPCL-PEG micelle were obtained in PBS (0.1 M, pH 7.4) and acetate buffer solutions $(0.1 \mathrm{M}, \mathrm{pH} 5.4)$ at $37{ }^{\circ} \mathrm{C}$. The results reveal an initial burst release of DOX for approximately $10 \mathrm{~h}$, followed by a sustained and slow release for over $60 \mathrm{~h}$ (Figure S1). The initial burst release of DOX from micelles is attributable to the diffusion of DOX that was located close to the surface of particles or within the hydrophilic shell, by the rapid degradation of the micelles [25]. Most of the DOX was released within a period of $60 \mathrm{~h}$ at $\mathrm{pH} 5.4$ and just less than $30 \%$ of the drug is released for both the $\mathrm{DMC}_{100}$ and $\mathrm{DMC}_{100} \mathrm{~F}$ at $\mathrm{pH}$ 7.4. The release of DOX from 4SPCL-PEG micelles at a $\mathrm{pH}$ value of 5.4 was faster than that of 4SPCL-PEG-Folic micelles. These results could be attributed to the re-protonation of the amino group of DOX and the faster degradation of the micelle core at 
lower $\mathrm{pH}$ values. This $\mathrm{pH}$-dependent release profile is of particular interest. It is expected that the greater part of DOX-loaded micelles will remain in the micelle cores for a period of time in plasma after intravenous administration and have the potential for prolonged DOX retention time in the blood circulation. However, a faster release may occur at low local $\mathrm{pH}$ surrounding the tumor site or by the more acidic environment inside the endosome and lysosome of tumor cells after cellular uptake of micelles through endocytosis.

Figure 1. Synthetic scheme of 4SPCL-PEG-FOL copolymer.
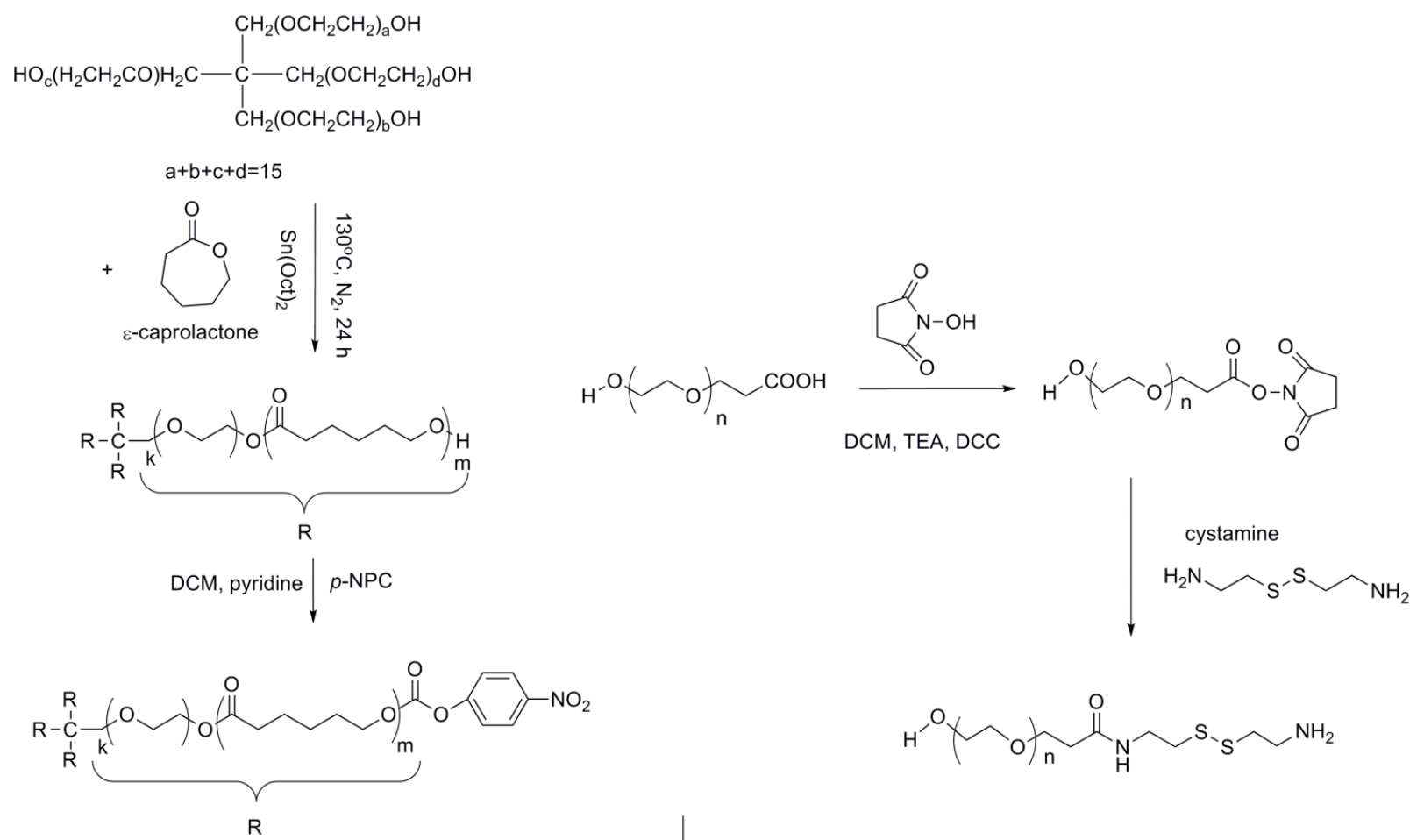

TEA, DMSO
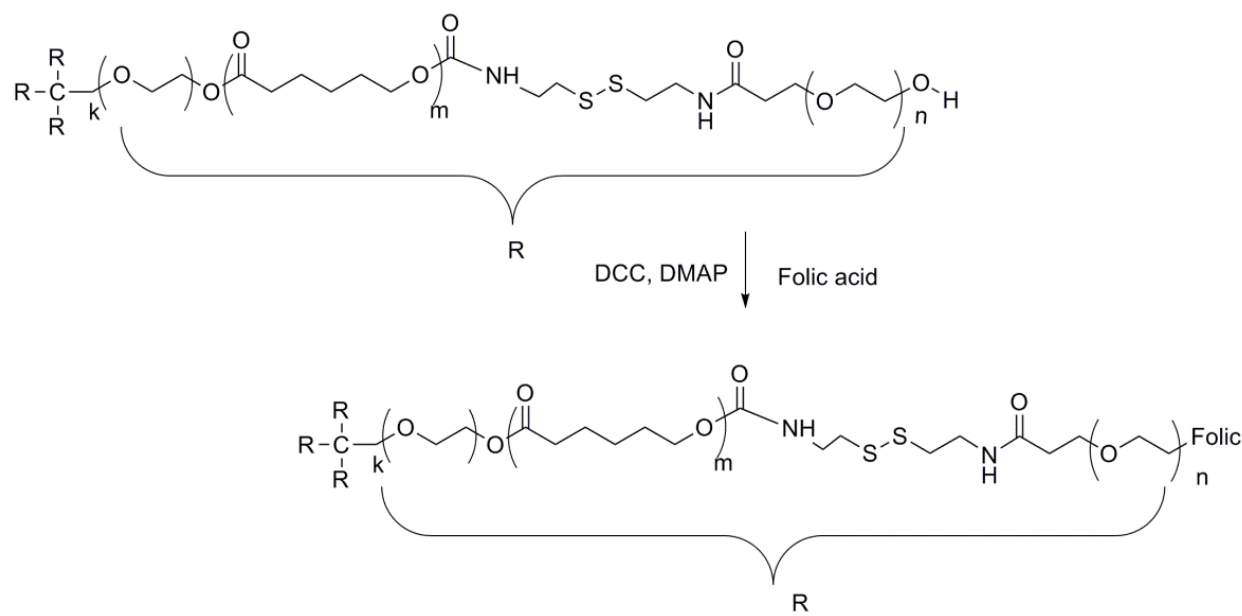

Table 1. Properties of prepared copolymer with various feed weight ratios of star-shaped PCL.

\begin{tabular}{cccccc}
\hline Sample & $\boldsymbol{M}_{\mathbf{w}}$ (theory) & $\boldsymbol{M}_{\mathbf{n}}{ }_{\text {NMR }}$ & Sample & $\boldsymbol{M}_{\mathbf{w}}$ (theory) & $\boldsymbol{M}_{\mathbf{n}}{ }_{\mathbf{N M R}}$ \\
\hline 4SPCL $_{50}$-PEG & 19,613 & 17,049 & 4SPCL $_{50}$-PEG-Folic & 21,521 & 17,168 \\
4SPCL $_{100}$-PEG & 25,313 & 23,398 & 4SPCL $_{100}$-PEG-Folic & 27,221 & 23,570 \\
4SPCL $_{150}$-PEG & 31,013 & 28,253 & 4SPCL $_{150}$-PEG-Folic & 30,161 & 28,680 \\
\hline
\end{tabular}


Table 2. The properties of doxorubicin (DOX)-loaded star-shaped micelle.

\begin{tabular}{|c|c|c|c|c|c|c|c|c|c|}
\hline \multicolumn{4}{|c|}{ Empty micelles } & \multicolumn{6}{|c|}{ Drug loading micelles } \\
\hline Sample & $\begin{array}{c}\text { Particle } \\
\text { size }(\mathrm{nm})^{a}\end{array}$ & $\begin{array}{l}\text { Zeta potential } \\
\qquad(\mathrm{mV})^{b}\end{array}$ & Poly Index & Sample & $\begin{array}{l}\text { Particle size } \\
\quad(\mathrm{nm})^{a}\end{array}$ & $\begin{array}{l}\text { Zeta potential } \\
\qquad(\mathrm{mV})^{b}\end{array}$ & $\begin{array}{l}\text { Poly } \\
\text { Index }\end{array}$ & $\operatorname{DLC}^{c}$ & $\begin{array}{l}\operatorname{DLE}^{c} \\
(\%)\end{array}$ \\
\hline $4 \mathrm{SPCL}_{50}-\mathrm{PEG}$ & $136.9 \pm 7.7$ & $-1.8 \pm 0.7$ & 0.29 & $\mathrm{DMC}_{50}$ & $96.9 \pm 9.7$ & $-2.8 \pm 0.7$ & 0.21 & 7.5 & 75 \\
\hline $4 \mathrm{SPCL}_{100}-\mathrm{PEG}$ & $172.3 \pm 1.5$ & $-1.4 \pm 0.5$ & 0.25 & $\mathrm{DMC}_{100}$ & $142.1 \pm 14.9$ & $-2.1 \pm 0.6$ & 0.19 & 8.8 & 88 \\
\hline $4 \mathrm{SPCL}_{150}-\mathrm{PEG}$ & $209.3 \pm 8.8$ & $-1.3 \pm 0.3$ & 0.27 & $\mathrm{DMC}_{150}$ & $145.2 \pm 14.1$ & $-1.9 \pm 0.6$ & 0.25 & 6.6 & 66 \\
\hline 4SPCL ${ }_{50}$-PEG-Folic & $125.3 \pm 2.6$ & $-1.9 \pm 0.1$ & 0.48 & $\mathrm{DMC}_{50} \mathrm{~F}$ & $126.2 \pm 1.1$ & $-3.4 \pm 0.15$ & 0.1 & 7.6 & 76 \\
\hline $4 \mathrm{SPCL}_{100}$-PEG-Folic & $133.4 \pm 7.4$ & $-2.3 \pm 0.9$ & 0.05 & $\mathrm{DMC}_{100} \mathrm{~F}$ & $128.7 \pm 8.9$ & $-3.9 \pm 0.15$ & 0.35 & 8.9 & 89 \\
\hline $4 \mathrm{SPCL}_{150}$-PEG-Folic & $174.2 \pm 1.9$ & $-2.0 \pm 0.5$ & 0.37 & $\mathrm{DMC}_{150} \mathrm{~F}$ & $123.1 \pm 7.9$ & $-2.4 \pm 0.19$ & 0.08 & 3.4 & 34 \\
\hline
\end{tabular}

\subsection{In Vitro Cytotoxicity of DOX-Loaded Micelles}

In this investigation, to elucidate the effect of the lethal dose and co-culturing time of DOX-loaded micelles on KB and MCF-7 cells, the cells were incubated with various concentrations of DOX equivalent from 0.01 to $20 \mu \mathrm{g} / \mathrm{mL}$ for various periods $(3,24$ and $48 \mathrm{~h})$. Figure 2 plots the cell viability of MCF-7 and KB cells that had been treated with DOX, DOX-loaded 4SPCL-PEG micelles and DOX-loaded 4SPCL-PEG-Folic micelles. The cell viabilities decreased significantly as the treatment time (3-48 h) or the DOX dose increased. The cell viabilities of MCF-7 and KB exceeded $80 \%$ after $3 \mathrm{~h}$ of treatment (Figure 2a,b). Free DOX and DOX-loaded micelles did not exhibit cytotoxicity after $3 \mathrm{~h}$ of incubation because of the lag phase of DOX [26]. Similar results were obtained after the incubation of DOX in other formulations for $3 \mathrm{~h}$ [20,27]. However, significant cytotoxicities were observed at $24 \mathrm{~h}$ and $48 \mathrm{~h}$. As shown in Figure 2, the cell viabilities decreased from $80 \%$ at $3 \mathrm{~h}$ to $40 \%$ and $15 \%$ at $24 \mathrm{~h}$ and $48 \mathrm{~h}$, respectively for KB and MCF-7 cells. The DOX-loaded micelles and free DOX exhibited almost the same effect to MCF-7 cells when the cells were incubated for $24 \mathrm{~h}$ (Figure 2c). However, free DOX had a stronger effect on KB cells than did DOX-loaded 4SPCL-PEG micelles or DOX-loaded 4SPCL-PEG-Folic micelles (Figure 2d). When KB and MCF-7 cells were incubated with DOX micelles and free DOX for $48 \mathrm{~h}$, the greater toxicity of free DOX was observed at DOX concentrations of under $5 \mu \mathrm{g} / \mathrm{mL}$ than those of DOX micelles and similar effects were observed when the DOX concentration exceeded $5 \mu \mathrm{g} / \mathrm{mL}$ (Figure 2e,f).

Additionally, we found that over $20 \%$ of $\mathrm{DOX}$ was released from $\mathrm{DMC}_{100}$ and $\mathrm{DMC}_{100} \mathrm{~F}$ micelles in the first $5 \mathrm{~h}$ of release experiment at $\mathrm{pH} 5.0$ (shown in the supporting information). In contrary, DOX in the micelles showed no burst release in the neutral medium ( $\mathrm{pH} 7.4)$. To correlate with cell viability for short incubation time (Figure 2a), the micelles and free DOX showed similar toxicity to MCF-7 cells. This can be attributed to the effect of burst release of DOX from the micelles. It is coincident to a report by Ostacolo et al. [28] that 4-arm star-PEG-PCL micelles displayed limited burst release of docetaxel, a potent chemotherapeutic agent for prostate cancer and breast cancer. The burst-released docetaxel behaving like free docetaxel can diffuse into the cancer cells. 
Figure 2. Cytotoxicities of human breast cancer cells (MCF-7)and human oral cavity carcinoma cells $(\mathrm{KB})$ cells, when cells were incubated with DOX-loaded micelle $\left(\mathrm{DMC}_{100}\right.$ and $\mathrm{DMC}_{100} \mathrm{~F}$ ) and free DOX: MCF-7 cells: (a) $3 \mathrm{~h}$; (c) $24 \mathrm{~h}$; and (e) $48 \mathrm{~h}$. KB cells: (b) $3 \mathrm{~h}$; (d) $24 \mathrm{~h}$; and (f) $48 \mathrm{~h}$.
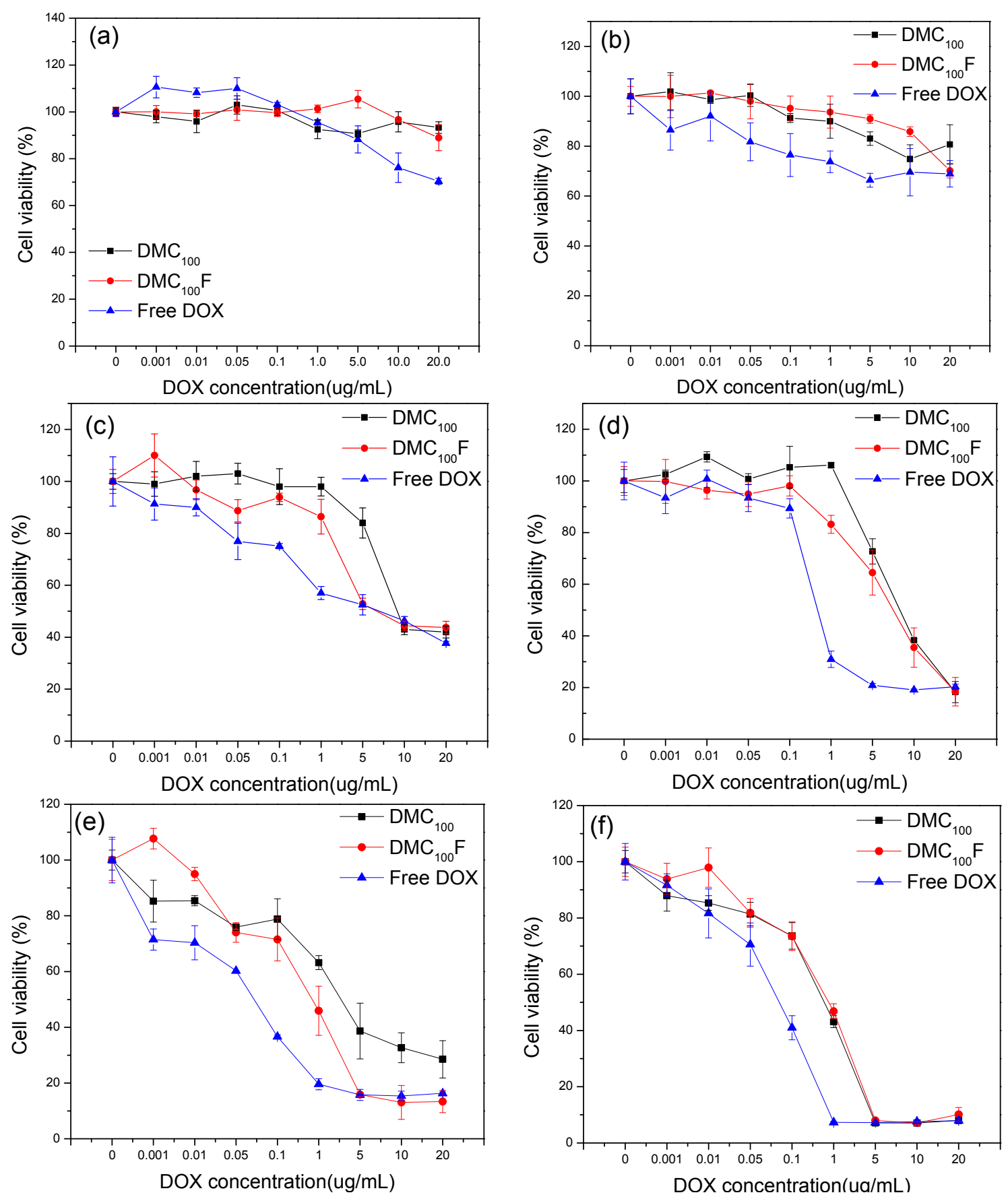

To elucidate further the role of folate in the cellular uptake of DOX-loaded 4SPCL-PEG-Folic micelles, the KB and MCF-7 cells were incubated with the micelles in a medium that contained free folic acid as an inhibitor of the folate receptor. As displayed in Figure 3, the cell viabilities of both cell lines in the presence of DOX-loaded 4SPCL-PEG-Folic micelles (No. 4) were lower than those in the presence of DOX-loaded 4SPCL-PEG-micelles (No. 3). The cell viabilities of KB cells were 37.4\% and $28.9 \%$ in the presence of nonfolic micelles and folic micelles, respectively; the cell viabilities of MCF-7 cells were similar. Moreover, the effect of pre-treatment of free folic acid on the intracellular 
uptake of either DOX-4SPCL-PEG-Folic micelle or DOX-4SPCL-PEG micelle was pronounced; The cell viability of DOX-loaded 4SPCL-PEG-Folic micelles in the presence of folic acid (No. 5) was higher than that in the presence of DOX-loaded 4SPCL-PEG-Folic micelle without a folic acid inhibitor (No. 4). Apparently the uptake of DOX in both of KB and MCF-7 cells was inhibited by free folic acid indicating that the folic micelles $\left(\mathrm{DMC}_{100} \mathrm{~F}\right)$ can specifically target to MCF-7 and $\mathrm{KB}$ cells via folate receptor-mediated endocytosis $[6,17,29]$.

Figure 3. Effect of free FA on the cell viabilities of MCF-7 and KB cells incubated with various DOX formulations for $24 \mathrm{~h}$ (DOX concentration: $10 \mu \mathrm{g} / \mathrm{mL}$ ).

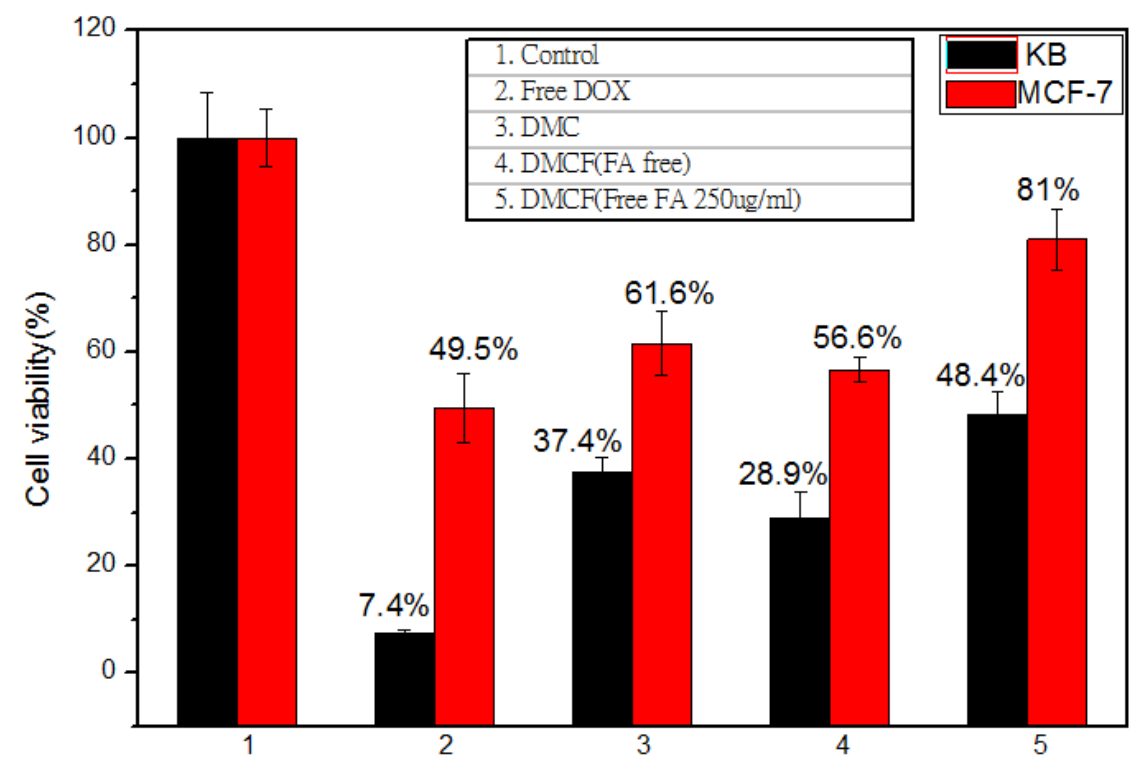

\subsection{Cellular Uptake of DOX-Loaded Micelles}

\subsubsection{Flow Cytometry}

To elucidate the relationships between the intracellular accumulations of DOX-micelles, and free DOX with incubation time and dose of DOX, the MCF-7 and KB cells were incubated with either free DOX or DOX-4SPCL-PEG-Folic micelles at DOX concentrations of 5 and $10 \mu \mathrm{g} / \mathrm{mL}$ for 3, 8 and $24 \mathrm{~h}$. The results thus reveal that the fluorescent intensities increased from 3 to $8 \mathrm{~h}$ of incubation, but the cellular uptake slightly increased from 8 to $24 \mathrm{~h}$ of incubation. Free DOX exhibited a more intense fluorescence in KB and MCF-7 cells than did DOX-loaded 4SPCL-PEG-Folic micelles or DOX-loaded 4SPCL-PEG-micelles after 8 or $24 \mathrm{~h}$ of incubation. Interestingly, the uptake by KB cells of DOX-loaded 4SPCL-PEG-Folic micelles was higher than that of DOX-loaded 4SPCL-PEG-micelles but was similar to that of free DOX after $3 \mathrm{~h}$ of incubation. Additionally, the DOX-loaded 4SPCL-PEG-Folic micelles were associated with a much lower cellular uptake of DOX by both cell lines than were the micelles without folic acid conjugation. The presence of folic acid in the culture medium did not affect the cellular uptake of DOX by MCF-7 cells following $24 \mathrm{~h}$ of incubation. However, the results of flow cytometry revealed that, after $24 \mathrm{~h}$ of incubation, a greater fraction of DOX was accumulated in $\mathrm{KB}$ cells when the micelles were conjugated with folate than when they were not conjugated with folate (Figures 4 and 5). These results suggest that the presence of folic acid in the culture medium competitively 
inhibited the binding of DOX-4SPCL-PEG-Folic micelles to folate receptor-positive KB cells, but that its effect on the binding to MCF-7 cells was very limited. These results suggest that DOX-4SPCL-PEG-Folic micelles were internalized by cells via a folate receptor-mediated endocytosis process. Note that the interpretation of flow cytometric data should be supplemented with the direct evidence of DOX fluorescence images. This is because fluorescence quench of DOX was reported from two origins: 1. When DOX binds to DNA in the nucleus [30]; 2. The shell of liposome and micelles [31]. As a result, the cellular uptake of DOX for relatively low nuclear DOX localization is under-estimated. Therefore, the following paragraph focuses on the confocal microscopy of endocytosis pathway of the free DOX and DOX-loaded micelles.

Figure 4. Flow cytometry histogram profile of $\mathrm{KB}$ cells that were incubated with free DOX, DOX-4SPCL-PEG-Folic micelle $\left(\mathrm{DMC}_{100} \mathrm{~F}\right)$ and DOX-4SPCL-PEG micelle $\left(\mathrm{DMC}_{100}\right)$ for 3 , 8 and $24 \mathrm{~h}$ with DOX concentration of $5 \mu \mathrm{g} / \mathrm{mL}(\mathbf{a}, \mathbf{c}, \mathbf{e})$ and $10 \mu \mathrm{g} / \mathrm{mL}(\mathbf{b}, \mathbf{d}, \mathbf{f})$. (Pink: control, Blue line: $\mathrm{DMC}_{100}$, Red: $\mathrm{DMC}_{100} \mathrm{~F}$, Black: free DOX, Green: free folic acid $\left.+\mathrm{DMC}_{100} \mathrm{~F}\right)$. The $y$-axis indicates the counts of the fluorescence intensity.

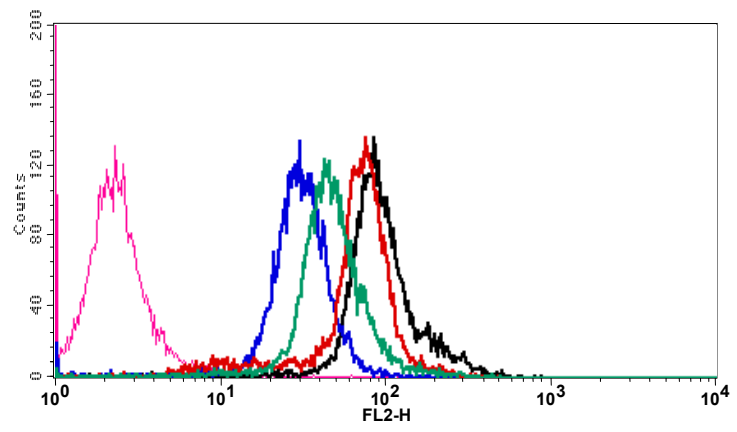

(a)

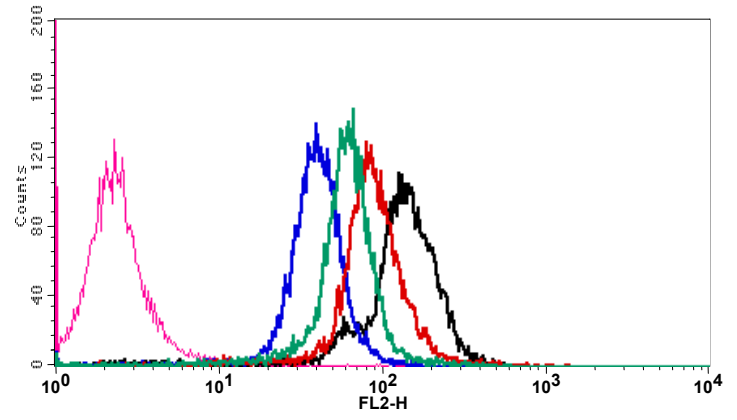

(c)

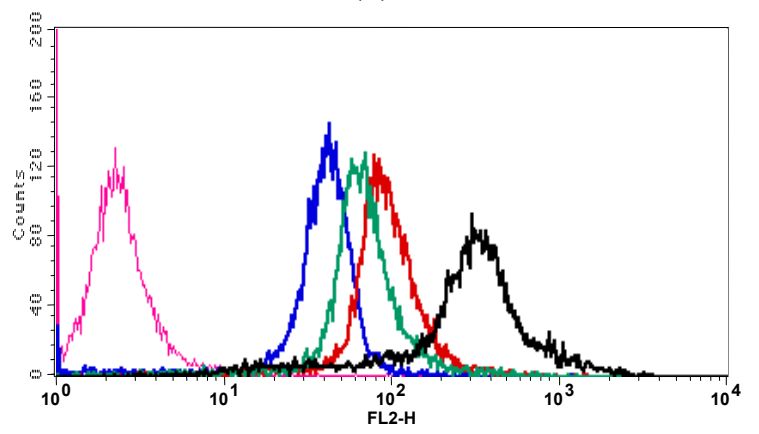

(e)

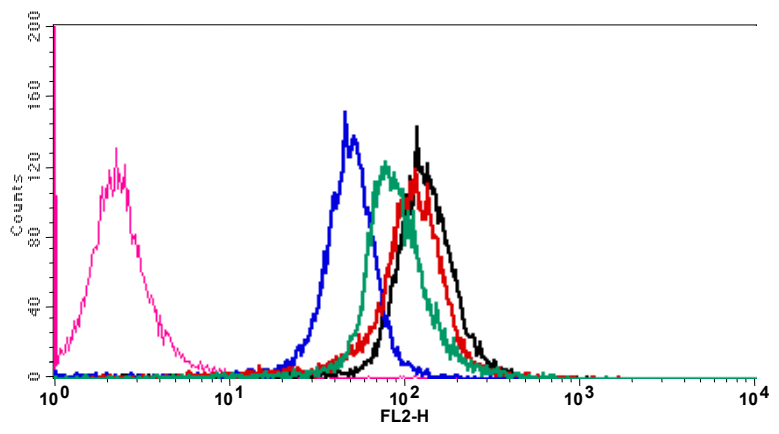

(b)

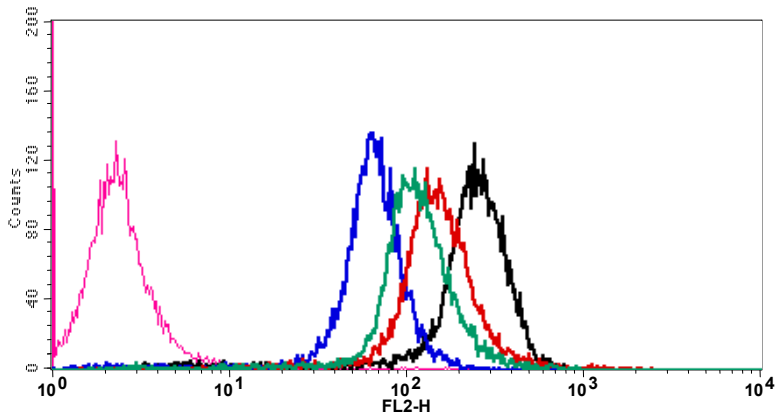

(d)

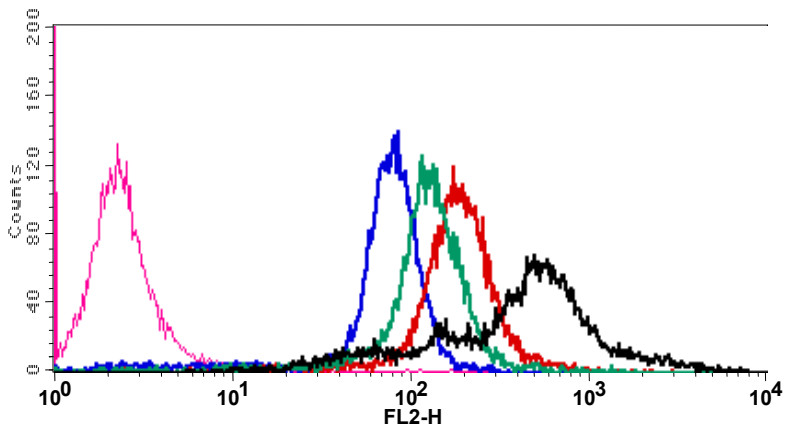

(f) 
Figure 5. Flow cytometry histogram profile of MCF-7 cells that were incubated with free DOX, DOX-4SPCL-PEG-Folic micelle $\left(\mathrm{DMC}_{100} \mathrm{~F}\right)$ and DOX-4SPCL-PEG micelle $\left(\mathrm{DMC}_{100}\right)$ for 3, 8 and $24 \mathrm{~h}$ with DOX concentration of $5 \mu \mathrm{g} / \mathrm{mL}(\mathbf{a}, \mathbf{c}, \mathbf{e})$ and $10 \mu \mathrm{g} / \mathrm{mL}$ (b,d,f). (Pink: control, Blue line: $\mathrm{DMC}_{100}$, Red: $\mathrm{DMC}_{100} \mathrm{~F}$, Black: free $\mathrm{DOX}$, Green: free folic acid $\left.+\mathrm{DMC}_{100} \mathrm{~F}\right)$. The $y$-axis indicates the counts of the fluorescence intensity.

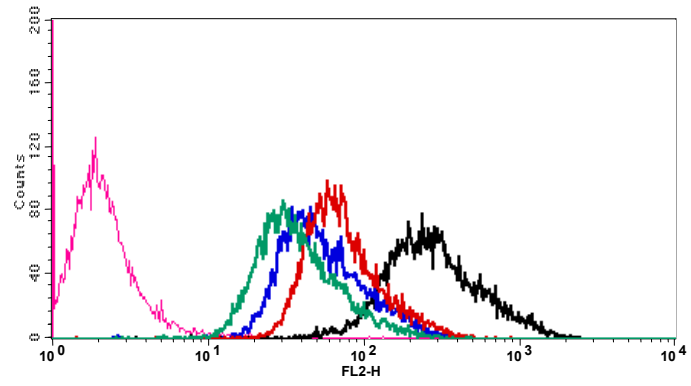

(a)

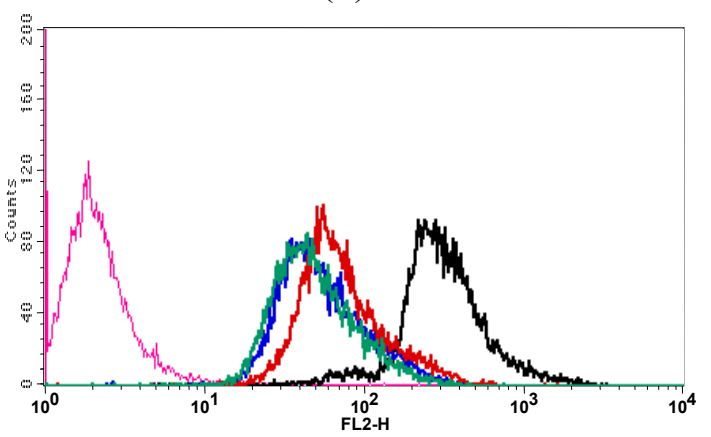

(c)

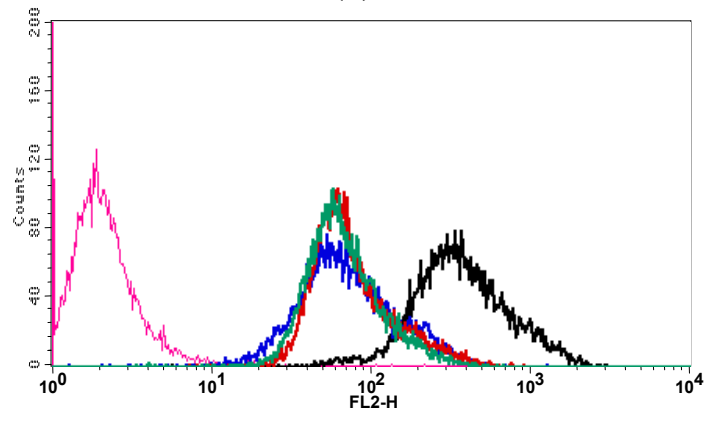

(e)

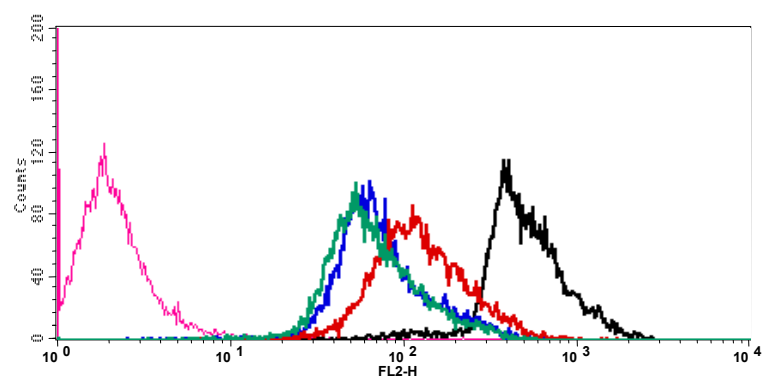

(b)

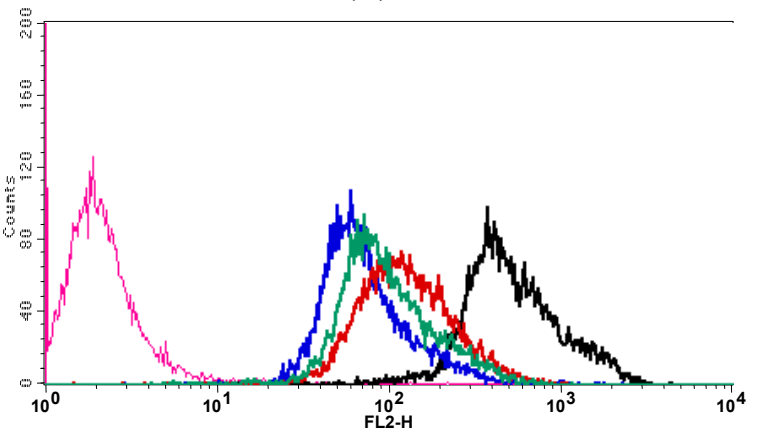

(d)

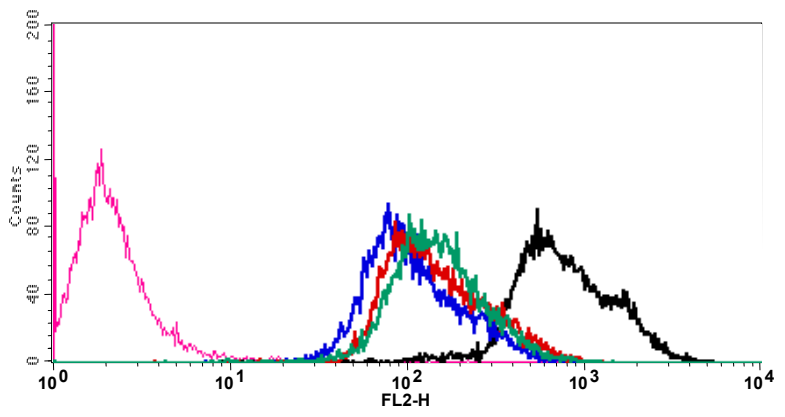

(f)

\subsubsection{Confocal Image of DOX-Loaded Micelles in KB and MCF-7 Cell Lines}

The cellular uptake and internalization of DOX-loaded 4SPCL-PEG-Folic micelles and DOX-loaded 4SPCL-PEG micelles in KB and MCF-7 cells were further examined using confocal microscopy. As presented in Figure 6, KB cells that were exposed to DOX-loaded 4SPCL-PEG-Folic micelles exhibited a higher fluorescence intensity of DOX than did MCF-7 cells. Strong DOX fluorescence was observed in the cytoplasm, revealing that the DOX-loaded micelles were internalized by the cells via endocytosis and that DOX was distributed throughout the cytoplasm after escaping from the endosome and/or the lysosome [3,32]. Furthermore, the DOX-loaded 4SPCL-PEG-Folic micelles had a greater fluorescence intensity than the DOX-loaded 4SPCL-PEG micelles in KB and MCF-7 cells. This result 
clearly reveals that the presence of folic acid on the surface of micelles increased the cellular uptake of DOX into the cells.

Figure 6. Confocal laser images of MCF-7 cells incubated with (a) DOX-4SPCL-PEG micelle; (b) DOX-4SPCL-PEG-Folic micelle; (c) KB cells incubated with DOX-4SPCL-PEG micelle; and (d) DOX-4SPCL-PEG-Folic micelle for $3 \mathrm{~h}$ with DOX concentration of $5 \mu \mathrm{g} / \mathrm{mL}$ (scale bar $50 \mu \mathrm{m}$ ).

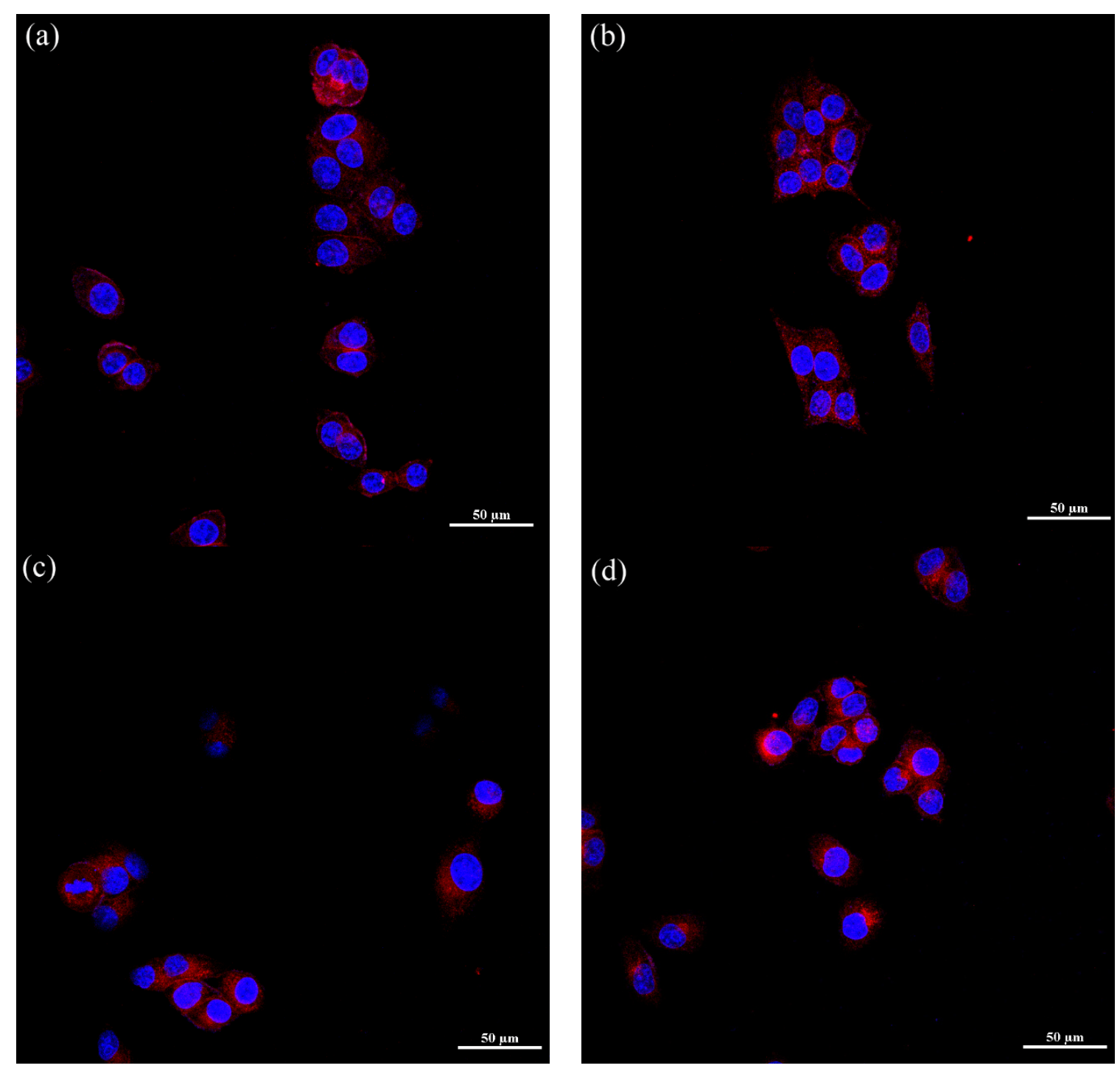

\subsubsection{Endocytosis Pathway}

Endocytosis is a basic cellular process that is exhibited by all cell types to internalize various molecules. It involves specialized proteins - clathrin and caveolin [13,14]. To identify the endocytic pathway that is involved in the uptake of 4SPCL-PEG-Folic micelles, cells were incubated with chlorpromazine to inhibit clathrin-mediated endocytosis; with $\mathrm{M} \beta C D$ to inhibit caveolae/lipid-raft mediated endocytosis; Cytochalasin D to inhibit macropinocytosis, and with phagocytosis and folic acid to inhibit FR-mediated endocytosis [13,14,33]. From the results thus obtained, Cytochalasin D did not influence the uptake of 4SPCL-PEG-Folic micelles by either KB or MCF-7 cells. The cellular uptakes were $99.23 \%$ and $99.7 \%$ for KB and MCF-7 cells, respectively. However, the inhibition by 
chlorpromazine of the uptake of the 4SPCL-PEG-Folic micelles in KB cells was higher than that in MCF-7 cells. M $\beta C D$ and folic acid markedly inhibited the uptake of 4SPCL-PEG-Folic micelles in both cell lines. When the cells were pretreated with $\mathrm{M} \beta C D$, $69 \%$ and $56 \%$ inhibition were observed for $\mathrm{KB}$ and MCF-7 cells, respectively, after $2 \mathrm{~h}$ of incubation. Hence, caveolin-dependent endocytosis mediates the uptake of 4SPCL-PEG-Folic micelles. Moreover, folic acid is an inhibitor of FR-mediated endocytosis. Consequently, the reduction in internalization of DOX-loaded-micelles in cells that had had pretreatment with folic acid was $57 \%$ and $26 \%$ for KB and MCF-7, respectively (Figure 7). These results demonstrate that caveolin-dependent endocytosis and folate receptor-mediated endocytosis mediate the uptake of 4SPCL-PEG-Folic micelles. Similar results have been obtained elsewhere [9,17], suggesting that the DOX-loaded micelles were herein mainly internalized via caveolae/lipid-raft-mediated endocytosis and clathrin-mediated endocytosis in $2 \mathrm{~h}$, and that the latter process consists of FR-mediated endocytosis and caveolae/lipid-raft mediated endocytosis. It was reported that MCF-7 cells could uptake paclitaxel-loaded $\mathrm{C}_{18}$-hyaluronic acid micelles conjugated with folate mainly via caveolae-mediated endocytosis while other pathways were also contributing to the drug uptake, e.g., multiple endocytosis pathway [34]. Hence the design of new polymeric micelles can follow this finding in order to engineer the drug carriers for quantitative drug delivery technology.

Figure 7. Effects of inhibitors on the internalization of DOX-loaded 4SPCL-PEG-Folic micelle (a) KB cell; and (b) MCF-7 cell.
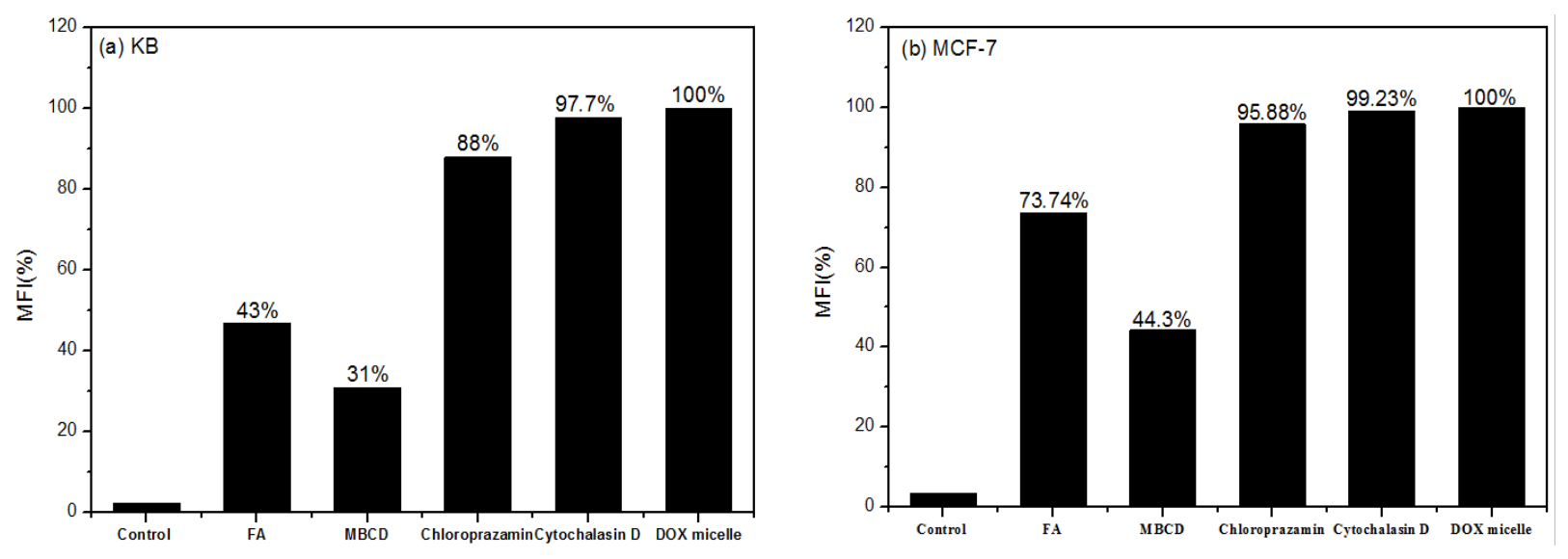

\section{Conclusions}

In this study, 4SPCL-PEG-Folic copolymer was synthesized using various feeding ratios of PCL. The copolymer structures were verified by ${ }^{1} \mathrm{H}$ NMR and FT-IR. The micelles that comprised the prepared 4SPCL-PEG-Folic copolymer were 97-209 $\mathrm{nm}$ in diameter. The in vitro drug release profiles from the micelles depended on $\mathrm{pH}$. The release of DOX from 4SPCL-PEG micelles at a $\mathrm{pH}$ value of 5.4 was faster than that from 4SPCL-PEG-Folic micelles. When DOX was loaded into 4SPCL-PEG-Folic micelles, the cytotoxicity and cellular uptake of the DOX-loaded folate micelles in KB and MCF-7 cells were greater than those of DOX-loaded micelles without the folate ligand. Finally, the folate micelles can deliver DOX into cells via FR-mediated endocytosis and caveolae/lipid-raft mediated endocytosis. 


\section{Acknowledgements}

We thank for the support of this work by Chung Yuan Christian University, Taiwan. The authors would like to thank the National Science Council of the Republic of China for financially supporting this research under Contract Nos. NSC101-2632-M-033-001-MY3 and NSC102-2221-E-033-012. Ted Knoy is appreciated for his editorial assistance.

\section{Author Contributions}

This paper includes the results of the master thesis research by Yu-Lun Li under the supervision of Ming-Fa Hsieh. Nguyen Van Cuong helps her during the experimental study. Ming-Fa Hsieh and Nguyen Van Cuong contributed in the analysis, manuscript preparation and revised the paper.

\section{Conflicts of Interest}

The authors declare no conflict of interest.

\section{References}

1. Byrne, J.D.; Betancourt, T.; Brannon-Peppas, L. Active targeting schemes for nanoparticle systems in cancer therapeutics. Adv. Drug Deliv. Rev. 2008, 60, 1615-1626.

2. Lu, Y.; Low, P.S. Folate-mediated delivery of macromolecular anticancer therapeutic agents. Adv. Drug Deliv. Rev. 2002, 54, 675-693.

3. Liu, S.Q.; Wiradharma, N.; Gao, S.J.; Tong, Y.W.; Yang, Y.Y. Bio-functional micelles self-assembled from a folate-conjugated block copolymer for targeted intracellular delivery of anticancer drugs. Biomaterials 2007, 28, 1423-1433.

4. Reddy, J.A.; Dorton, R.; Westrick, E.; Dawson, A.; Smith, T.; Xu, L.-C.; Vetzel, M.; Kleindl, P.; Vlahov, I.R.; Leamon, C.P. Preclinical evaluation of ec145, a folate-vinca alkaloid conjugate. Cancer Res. 2007, 67, 4434-4442.

5. Hilgenbrink, A.R.; Low, P.S. Folate receptor-mediated drug targeting: From therapeutics to diagnostics. J. Pharm. Sci. 2005, 94, 2135-2146.

6. Yang, S.J.; Lin, F.H.; Tsai, K.C.; Wei, M.F.; Tsai, H.M.; Wong, J.M.; Shieh, M.J. Folic acid-conjugated chitosan nanoparticles enhanced protoporphyrin ix accumulation in colorectal cancer cells. Bioconjugate Chem. 2010, 21, 679-689.

7. Wu, J.; Liu, Q.; Lee, R.J. A folate receptor-targeted liposomal formulation for paclitaxel. Int. J. Pharm. 2006, 316, 148-153.

8. Xu, B.; Yuan, J.; Ding, T.; Gao, Q. Amphiphilic biodegradable poly( $\varepsilon$-caprolactone)-poly(ethylene glycol)-poly( $\varepsilon$-caprolactone) triblock copolymers: Synthesis, characterization and their use as drug carriers for folic acid. Polym. Bull. 2010, 64, 537-551.

9. Lu, T.; Sun, J.; Chen, X.; Zhang, P.; Jing, X. Folate-conjugated micelles and their folate-receptor-mediated endocytosis. Macromol. Biosci. 2009, 9, 1059-1068.

10. Kim, D.; Gao, Z.G.; Lee, E.S.; Bae, Y.H. In vivo evaluation of doxorubicin-loaded polymeric micelles targeting folate receptors and early endosomal $\mathrm{pH}$ in drug-resistant ovarian cancer. Mol. Pharm. 2009, 6, 1353-1362. 
11. Zhang, Z.; Yao, J. Preparation of irinotecan-loaded folate-targeted liposome for tumor targeting delivery and its antitumor activity. AAPS PharmSciTech 2012, 13, 802-810.

12. Zhao, F.; Zhao, Y.; Liu, Y.; Chang, X.; Chen, C.; Zhao, Y. Cellular uptake, intracellular trafficking, and cytotoxicity of nanomaterials. Small 2011, 7, 1322-1337.

13. Sahay, G.; Alakhova, D.Y.; Kabanov, A.V. Endocytosis of nanomedicines. J. Control. Release 2010, 145, 182-195.

14. Bareford, L.M.; Swaan, P.W. Endocytic mechanisms for targeted drug delivery. Adv. Drug Deliv. Rev. 2007, 59, 748-758.

15. Dauty, E.; Remy, J.-S.; Zuber, G.; Behr, J.-P. Intracellular delivery of nanometric DNA particles via the folate receptor. Bioconjugate Chem. 2002, 13, 831-839.

16. Hillaireau, H.; Couvreur, P. Nanocarriers' entry into the cell: Relevance to drug delivery. Cell. Mol. Life Sci. 2009, 66, 2873-2896.

17. Cuong, N.-V.; Li, Y.-L.; Hsieh, M.-F. Targeted delivery of doxorubicin to human breast cancers by folate-decorated star-shaped PEG-PCL micelle. J. Mater. Chem. 2012, 22, 1006-1020.

18. Cuong, N.V.; Hsieh, M.F.; Chen, Y.T.; Liau, I. Doxorubicin-loaded nanosized micelles of a star-shaped poly(e-caprolactone)-polyphosphoester block co-polymer for treatment of human breast cancer. J. Biomater. Sci. Polym. Ed. 2011, 22, 1409-1426.

19. Cuong, N.V.; Hsieh, M.F.; Chen, Y.T.; Liau, I. Synthesis and characterization of PEG-PCL-PEG triblock copolymers as carriers of doxorubicin for the treatment of breast cancer. J. Appl. Polym. Sci. 2010, 117, 3694-3703.

20. Cuong, N.V.; Jiang, J.L.; Li, Y.L.; Chen, J.R.; Jwo, S.C.; Hsieh, M.F. Doxorubicin-loaded PEG-PCL-PEG micelle using xenograft model of nude mice: Effect of multiple administration of micelle on the suppression of human breast cancer. Cancers 2011, 3, 61-78.

21. Aliabadi, H.M.; Mahmud, A.; Sharifabadi, A.D.; Lavasanifar, A. Micelles of methoxy poly(ethylene oxide)- $b$-poly( $\varepsilon$-caprolactone) as vehicles for the solubilization and controlled delivery of cyclosporine A. J. Control. Release 2005, 104, 301-311.

22. Cui, J.; Li, C.; Guo, W.; Li, Y.; Wang, C.; Zhang, L.; Zhang, L.; Hao, Y.; Wang, Y. Direct comparison of two pegylated liposomal doxorubicin formulations: Is auc predictive for toxicity and efficacy? J. Control. Release 2007, 118, 204-215.

23. Wang, Y.; Wang, Y.; Xiang, J.; Yao, K. Target-specific cellular uptake of taxol-loaded heparin-peg-folate nanoparticles. Biomacromolecules 2010, 11, 3531-3538.

24. Shuai, X.; Ai, H.; Nasongkla, N.; Kim, S.; Gao, J. Micellar carriers based on block copolymers of poly(ع-caprolactone) and poly(ethylene glycol) for doxorubicin delivery. J. Control. Release 2004, 98, 415-426.

25. Allen, C.; Maysinger, D.; Eisenberg, A. Nano-engineering block copolymer aggregates for drug delivery. Colloid Surf. B Biointerfaces 1999, 16, 3-27.

26. Minotti, G.; Menna, P.; Salvatorelli, E.; Cairo, G.; Gianni, L. Anthracyclines: Molecular advances and pharmacologic developments in antitumor activity and cardiotoxicity. Pharmacol. Rev. 2004, 56, 185-229. 
27. Upadhyay, K.K.; Bhatt, A.N.; Mishra, A.K.; Dwarakanath, B.S.; Jain, S.; Schatz, C.; le Meins, J.F.; Farooque, A.; Chandraiah, G.; Jain, A.K.; et al. The intracellular drug delivery and anti tumor activity of doxorubicin loaded poly(gamma-benzyl L-glutamate)- $b$-hyaluronan polymersomes. Biomaterials 2010, 31, 2882-2892.

28. Ostacolo, L.; Marra, M.; Ungaro, F.; Zappavigna, S.; Maglio, G.; Quaglia, F.; Abbruzzese, A.; Caraglia, M. In vitro anticancer activity of docetaxel-loaded micelles based on poly(ethylene oxide)-poly(e-caprolactone) block copolymers: Do nanocarrier properties have a role. J. Control. Release 2010, 148, 255-263.

29. Zhao, H.; Duong, H.H.P.; Yung, L.Y.L. Folate-conjugated polymer micelles with pH-triggered drug release properties. Macromol. Rapid Commun. 2010, 31, 1163-1169.

30. Mohan, P.; Rapoport, N. Doxorubicin as a molecular nanotheranostic agent: Effect of doxorubicin encapsulation in micelles or nanoemulsions on the ultrasound-mediated intracellular delivery and nuclear trafficking. Mol. Pharm. 2010, 7, 1959-1973.

31. Tsukioka, Y.; Matsumura, Y.; Hamaguchi, T.; Koike, H.; Moriyasu, F.; Kakizoe, T. Pharmaceutical and biomedical differences between micellar doxorubicin (NK911) and liposomal doxorubicin (Doxil). Jpn. J. Cancer Res. 2002, 93, 1145-1153.

32. Zhao, H.; Yung, L.Y.L. Selectivity of folate conjugated polymer micelles against different tumor cells. Int. J. Pharm. 2008, 349, 256-268.

33. Chiu, Y.L.; Ho, Y.C.; Chen, Y.M.; Peng, S.F.; Ke, C.J.; Chen, K.J.; Mi, F.L.; Sung, H.W. The characteristics, cellular uptake and intracellular trafficking of nanoparticles made of hydrophobically-modified chitosan. J. Control. Release 2010, 146, 152-159.

34. Liu, Y.; Sun, J.; Cao, W.; Yang, J.; Lian, H.; Li, X.; Sun, Y.; Wang, Y.; Wang, S.; He, Z. Dual-targeting folate-conjugated hyaluonic acid polymeric micelles for paclitaxel delivery. Int. J. Pharm. 2011, 421, 160-169.

(C) 2014 by the authors; licensee MDPI, Basel, Switzerland. This article is an open access article distributed under the terms and conditions of the Creative Commons Attribution license (http://creativecommons.org/licenses/by/3.0/). 